
\title{
$\begin{array}{ll}\text { Research Square } & \begin{array}{l}\text { Preprints are preliminary reports that have not undergone peer review. } \\ \text { They should not be considered conclusive, used to inform clinical practice, } \\ \text { or referenced by the media as validated information. }\end{array}\end{array}$
}

\section{A Retrospective Cohort Study of Anterior Fontanelle Delayed Closure in Healthy Infants and Its Associated Factors}

MengYan Tang

Sichuan University West China Second University Hospital https://orcid.org/0000-0001-8286-5929

Fei Xiong

Sichuan University West China Second University Hospital

Ping Li

Sichuan University West China Second University Hospital

Limin Zeng

Sichuan University West China Second University Hospital

SuFei Yang ( $\nabla$ ysfetbj@163.com)

Research

Keywords: Anterior Fontanelle, Child Health, Physical Growth and Development

Posted Date: July 14th, 2020

DOI: https://doi.org/10.21203/rs.3.rs-41012/v1

License: @ (i) This work is licensed under a Creative Commons Attribution 4.0 International License. Read Full License 


\section{Abstract}

Background: Anterior fontanelle (AF) is a regular feature of infant development, and delayed closure of AF (AFDC) is highly valued in the clinical of child health care.

Methods: A retrospective cohort study with a 3-year follow-up was conducted to understand the occurrence of AFDC in healthy infants and its associated factors.

Results: 792 infants were examined, 61 infants had AFDC and the incidence rate of AFDC in healthy infants was $7.71 \%$. By the age of 24 months, $92.29 \%$ of infants had AF closure, with $99.87 \%$ achieving closure before 36 months old. Form 1 to 36 months age, the median AF size of AFDC group was significantly larger than that of AF normal closure (AFNC) group; from 6 to 36 months age, the median weight as well as length of AFDC group were all lower than those of AFNC group. There was no difference in head circumference between the two groups. The birth weight $(\mathrm{OR}=1.001)$, birth length (OR=0.778), AF size at 1 month $(\mathrm{OR}=4.196)$, and gender $(\mathrm{OR}=1.851)$ were associated factors of AFDC.

Conclusion: AFDC in healthy infants was determined to be within a normal range for AF development and was not related to any disease. AF development was correlated to weight as well as length, but not correlated to head circumference. Congenital factors such as heavier birth weight, longer birth length, larger AF size at birth, and being male were associated with AFDC.

\section{Brief Points}

\section{What is already known on this topic?}

- Delayed closure of anterior fontanelle (AFDC) may indicate some pathology, however, pediatricians found that some infants with AFDC had healthy growth and a normal developmental trajectory, which indicates that there may be a subset of AFDC infants who are normal variants of those children with healthy AF closure and who do not have any dysmorphic features and/or other pathological clinical signs. Currently, we have no understanding regarding the proportion of this subset of infants and the causes behind this subset.

- More than $90 \%$ of children have AF closure before 24 months, but most previous research stopped at the age of 24 months when observing AF development in children.

- AF development may be related with weight, height or length, head circumference development.

\section{What this paper adds?}

- The incidence rate of AFDC in healthy infants was $7.71 \%$, which was determined to be within a normal range for AF development and not related to any diseases. And we determined that factors related to AFDC in healthy infants included the following congenital factors: AF size at birth, heavier weight, longer length, and being male.

- By the age of 24 months, $92.29 \%$ of infants had AF closure, with $99.87 \%$ achieving closure before 36 months old.

- AF development was significantly correlated to weight, length and height, but not to head circumference.

\section{Introduction}

Anterior fontanelle (AF) lies between the frontal and parietal bones of the skull and is normally described as "a curved rhomboid, nonmineralized fibrous membrane in the cranial vault at the convergence of the coronal, sagittal, and metopic sutures in the developing infant [1]". AF palpation during a pediatric physical examination is necessary, as the size, shape, and whether the AF is closed may indicate underlying pathologies [2-5]. For instance, a large AF (in diameter) may suggest diseases as osteogenesis imperfecta, elevated intracranial pressure, achondroplasia, congenital hypothyroidism, or other skeletal or growth related anomalies [2,3]. Contrastingly, a small AF (in diameter) or an AF that closes too quickly may indicate craniosynostosis, hyperthyroidism, microcephalia, and/or other aberrant cerebral development diseases [4]. Besides, delayed closure of the anterior fontanelle (AFDC) may reflect elevated intracranial pressure, congenital hypothyroidism, achondroplasia, Down syndrome, Apert's syndrome, rickets, dermoid cyst, or other underlying conditions [5].

Current pediatric textbooks do not have follow one specific definition for AFDC, most only state that AF should be closed at 1-1.5 years old and no later than 2 years of age [4]. And there are few studies related to AFDC, resulting in a notable lack of epidemiological investigations and analysis of relevant factors associated with AFDC. However, in the course of standard pediatric care, pediatricians found that some AFDC infants had healthy growth and a normal developmental trajectory [6]. This indicates that there may be a subset of AFDC infants who are normal variants of those children with healthy AF closure and who do not have any dysmorphic features and other pathological clinical signs [7]. Although this might be true, we currently have no understanding regarding the proportion of this subset of infants and the causes behind this subset. Therefore, we conducted a 3-year retrospective cohort study to better understand the occurrence and associated factors of AFDC in healthy infants.

\section{Methods}

\section{Study Design}

This study was a retrospective cohort study. All infants were born between January 1, 2015 and December 31, 2015 and followed for three years in the Child Health Department of the West China Second Hospital at Sichuan University. Exclusion criteria were as follows: (1) Imaging examination during maternal pregnancy indicating abnormal brain development, such as hydrocephalus; (2) Head injury or scalp hematoma at birth; (3) Intracranial diseases, such as 
pituitary tumors; (4) Skeletal metabolic disease, such as rickets; (5) Endocrine disease affecting growth and development, such as congenital hypothyroidism; (6) Other serious diseases affecting growth and development, such as malignant tumors; (7) Missing or incomplete data.

According to previous studies, more than $90 \%$ of children have AF closure before 24 months [7-9]. Given this, we used AF closure at 24 months as the demarcation for infants with normal closure of the AF (AFNC) and those with delayed closure of the AF (AFDC). In short, infants with AF closure after 24 months were placed in the AFDC group; all others were placed in the AFNC group.

After data screening and expulsions, a total of 792 infants were enrolled, including 731 infants with AFNC and 61 infants with AFDC. All information regarding these 792 infants were extracted from the Child Health Electronic Information System of West China Second Hospital at Sichuan University. Information included physical growth and development data, such as: AF size, weight, length and height, and head circumference at various ages (0, 1, 6, 12, 18, 24, 30, and 36 months). Perinatal and nutritional information was also gathered, including: Gender, delivery mode, gestational age, fetus numbers, maternal gravidity, maternal parity, VA and VD average supplement before 2 years old, and the time of introducing complementary food.

\section{Analysis and Ethical Consideration}

SPSS 22.0 statistical software was used to analyze the data. Number and percentage were used to describe the trend in AF closure across all 792 infants. When comparing the AFNC and AFDC groups with regards to physical growth and development, a Shapiro-Wilk test was used for normal statistical analysis; a Mann-Whitney $\mathrm{U}$ test was used to analyze the difference between two groups. Chi-Squared and Mann-Whitney U tests were both used for univariate analysis to determine significant variables associated with AFDC. A binary logistic regression was used for multivariate analysis, in which categorical variables were processed as dummy variables and continuous variables were used as original values. A p-value less than or equal to 0.05 was considered statistically significant.

Ethical approval was obtained from the Ethics Committee of the West China Second Hospital at Sichuan University. All information used in the study will remain confidential and be used only for the purposes of the scientific work presented here.

\section{Results}

\section{AFDC occurrence in healthy infants}

Among the 792 infants included in the study, 61 infants had AFDC. Given this, the incidence rate of AFDC in healthy infants was calculated as $7.71 \%$. In addition, we found that most infants had AF closure from 12-18 months old; by the age of 24 months, $92.29 \%$ of infants had AF closure and by 36 months, $99.87 \%$ infants had closure. AF closure times are shown in Table 1 and the trend in AF closure is shown in Figure 1.

\section{Difference in physical growth and development between AFNC and AFDC}

Here, we found a significant difference in AF size between the AFNC and AFDC groups from the age of 1 to 36 months. Median AF size in the AFDC group was always notably larger than that in the AFNC group. Moreover, there were also significant differences in weight and length between the two groups. More specifically, the median weight and length in the AFDC group were all lower than those of the AFNC group, and this difference only began to differentiate at the age of 6 months. No significant difference was found in head circumference between the two groups. The values and differences in AF size, weight, length and head circumference between the two groups are shown in Table 2.

\section{Associated factors in AFDC in healthy infants}

The univariate analysis revealed that birth weight $\left(X^{2}=21.218, p<0.001\right)$ and gestational age $\left(X^{2}=5.262, p=0.022\right)$ were all significantly associated with $A F D C$, the results are summarized in Table 3. And the Logistic regression revealed that heavier birth weight $(O R=1.001, p=0.002)$, longer birth length (OR=0.778, $p=0.005)$, larger AF size at 1 month $(O R=4.196, p<0.001)$, and being male $(O R=1.851, p=0.033)$ were all associated with $A F D C$ in normal infants. These data are shown in Table 4.

\section{Discussion}

According to the results of this three year follow-up regarding the AF development, we found that there $92.29 \%$ of included infants had AF closure before the age of 24 months. These data are similar to those of a study conducted by Liu et al. [10], who reported $94.2 \%$ of infants had AF closure before the age of 24 months, and which were based on a cross-sectional survey of 104,147 children from 9 urban cities in China. However, Kiesler et al. [3] found that approximately $96 \%$ of infants had AF closure before 24 months. The differences between these studies may be explained by ethnic divergence. The results of our study also showed that by the age of 36 months, $99.87 \%$ of infants had AF closure. Notably, most previous research stopped at the age of 24 months when observing AF development in children. Our data may help start filling this gap in developmental understanding. In addition, there were 61 infants among the 792 infants with AFDC, resulting in an AFDC incidence rate of $7.71 \%$ in healthy infants. This finding is consistent with a relevant study reporting the AFDC incidence range from $4-7 \%[8,10,11]$, which suggests that the time of AF closure in some infants is later than 24 months old, and with some not even having closure after 36 months. The proportion of this AFCD population is approximately $7.71 \%$. As the infants in this study were healthy and within normal ranges for physical growth and development, we concluded that this occurrence could be interpreted as normal variation within AF development and not related to any diseases. 
Moreover, we found that the median AF size of the AFDC group was larger than that of AFNC group, indicating that AFDC in normal infants was related to congenital AF enlargement. The larger the birth AF size is, and given normal brain development and skull osteogenesis, the longer time needed for total AF closure. Our results also showed that the median weight and length of AFDC group were lighter and shorter than those of AFNC group, and there was no significant difference in head circumference between the two groups. Collectively, these results suggest that AF development may be correlated to weight and length development rather than head circumference. These findings are also consistent with those of Liu et al. [10], who also found no correlation between the time of AF closure and head circumference. However, similar research conducted by Kumar et al. [12] and Oumer et al. [13] found that AF size was significantly related to only newborn weight. Comparatively, Wu Ting et al. [9] reported that the development of AF size was not related to height, weight or head circumference. As for why there was the lack of a correlation between AF development and head circumference, We speculate this was mainly due to the existence of bone seams in the infant skull, which are connected by elastic, membranous, fiber tissue. With the continuous ossification and maturation of the skull, the AF gradually closes, but the bone seams can still expand for providing the space for brain development, and the head circumference can still increase[4,10]. Therefore, it makes sense that the time of AF closure is not directly related to head circumference.

Finally, our results showed that heavier birth weight, longer birth length, larger congenital AF size, and being male were associated with AFDC. Previous studies by Roy et al.confirmed that AF size at birth was correlated to birth weight [14]. Perera et al. showed that AF size at birth was significantly related to birth length [15], and Oumer et al. reported that AF size in male infants was larger than that in female infants [13]. we speculated that this may have been related to maternal nutritional status during pregnancy. If the pregnant mother was able to provide sufficient nutrition for the developing fetus in the later period of pregnancy, which would mean that there were sufficient reserves of minerals and trace elements (e.g., calcium and phosphorus), and lowering the likelihood for AFDC. Interestingly, our results showed both Vitamin A/D supplements and the time of introducing complementary food were not associated with AFDC. We hypothesize this was due to the fact that our research was conducted in an economically developed city in China, with parents who had the financial capacity to provide their infants with enough vitamin supplements and a balanced diet. Given this, there was no significant difference between AFDC group and AFNC group. However, this result also indicated that a diagnosis AFDC should also be combined with an assessment of clinical symptoms and a biochemical examination, and large doses of vitamin D should not be blindly preferred in the treatment of AFDC.

There are some limitations to this study. First, it was conducted as a single-center study, which was likely not representative and may have introduced selection bias. As this study was also retrospective, sample size and data type were limited; given this, it would be advisable to conduct a case-control study of AFDC in the future.

\section{Conclusion}

This study presented an analysis of delayed closure of the anterior fontanelle (AFDC) in healthy infants with conducting a 3-year follow up retrospective cohort study. The results showed the incidence rate of AFDC in healthy infants was $7.71 \%$, which was determined to be within a normal range for AF development and not related to any diseases. AF development was significantly related to weight and length, but not to head circumference. Variables such as heavier birth weight, longer birth length, larger AF size at birth, and being male were all associated with AFDC.

\section{Abbreviations}

AF: Anterior Fontanelle

AFDC: Anterior Fontanelle Delayed Closure

AFNC: Anterior Fontanelle Normal Closure

\section{Declarations}

\section{Ethical Approval and Consent to participate}

Ethical approval was obtained from the Ethics Committee of the West China Second Hospital at Sichuan University. All information used in the study will remain confidential and be used only for the purposes of the scientific work presented here.

\section{Consent for publication}

All authors gave final approval of the version to be published, and agree to be accountable for all aspects of the work.

\section{Availability of data and materials}

Not applicable

\section{Competing interests}

We declare that we have no competing interests. 


\section{Funding}

This work was supported by the Chinese National Natural Science Foundation of Youth Fund[81701540].

\section{Authors' contributions}

Author contributions and Consent for publication: All authors contributed to data analysis, drafting or revising the article.

\section{Acknowledgements}

We thank professor Fan-Yang for her kindness guidance and suggestion for this study.

\section{References}

1. Duc G, Largo RH, Anterior fontanel: size and closure in term and preterm infants.[J] .Pediatrics, 1986, 78: 904-908.

2. Popich GA, Smith DW. Fontanels: range of normal size. J Pediatr, 1972, 80(5):749-752.

3. Kiesler J, Ricer R. The abnormal fontanel. Am Fam Physician, 2003, 67(12):2547-2552.

4. D'Antoni AV, Donaldson OI, Schmidt C, et al. Comprehensive review of the anterior fontanelle: embryology, anatomy, and clinical considerations. Childs Nerv Syst,2017, 33(6):909-914.

5. Bharti P, Gupta U, Bharti SK. Rare case of anterior fontanelle epidermoid/dermoid. J Pediatr Neurosci,2015, 10(3):247-249.

6. De Gaetano HM, De Gaetano JS. Persistent open anterior fontanelle in a healthy 32-month-old boy. J Am 0steopath Assoc,2002, $102(9): 500-501$.

7. Pindrik J, Ye X, Ji BG, et al. Anterior fontanelle closure and size in full-term children based on head computed tomography. Clin Pediatr (Phila),2014, 53(12):1149-1157.

8. Pedroso FS, Rotta N, Quintal A, et al. Evolution of anterior fontanel size in normal infants in the first year of life. J Child Neurol, 2008, 23(12):1419-1423.

9. Wu T, Li HQ. Changes of anterior fontanel size in children aged 0 - 2 years. Zhonghua Er Ke Za Zhi,2012, 50(7):493-497.

10. Liu Y, Li H, Zhang YQ,et al. Development of anterior fontanelle in Chinese children in 2015. Zhonghua Er Ke Za Zhi, 2017, 55(8):602-607.

11. Acheson RM, Jefferson E. Some Observations on the Closure of the Anterior Fontanelle[J]. Archives of Disease in Childhood, 1954, 29(145):196-198.

12. Kumar J, Singh A. Anterior fontanelle size in healthy indian late preterm and full term newborns[J]. Indian J Pediatr, 2019, 86(2):204-205.

13. Oumer M, Guday E, Teklu A, et al.Anterior fontanelle size among term neonates on the first day of life born at University of Gondar Hospital, Northwest Ethiopia[J]. PLoS One,2018, 13(10):e0202454.

14. Roy S, Tewari V, Equbal J. Anterior fontanelle size in healthy Indian late preterm and full term Newborns[J]. Indian J Pediatr, 2018, 85(11):984-988.

15. Perera PJ, Wickramasinghe AR, Ranathunga N, et al. Statistical characteristics of anterior fontanelle size at birth of term Sri Lankan new borns: a descriptive cross sectional study[J]. Ceylon Med J, 2013, 58(3):96-100.

\section{Tables}

Table 1

the closure time of $\mathrm{AF}(\mathrm{N}=792)$

\begin{tabular}{|lllll|}
\hline Month & Numbers of closed & Closed & Unclosed & Percentage of AF closure \\
\hline $0-6$ & 2 & 2 & 790 & $0.25 \%$ \\
\hline $6-12$ & 105 & 107 & 685 & $13.51 \%$ \\
\hline $12-18$ & 420 & 527 & 265 & $66.54 \%$ \\
\hline $18-24$ & 204 & 731 & 61 & $92.29 \%$ \\
\hline $24-30$ & 56 & 787 & 5 & $99.49 \%$ \\
\hline $30-36$ & 4 & 791 & 1 & $99.87 \%$ \\
\hline AF, anterior fontanelle & & & \\
\hline
\end{tabular}


Table 2

The comparison of physical growth and development in AFNC and AFDC infants( $N=792)$

\begin{tabular}{|c|c|c|c|c|c|c|c|c|c|c|}
\hline \multirow[t]{4}{*}{ Month } & \multicolumn{3}{|c|}{ Anterior Fontanelle } & \multicolumn{3}{|l|}{ Weight } & \multicolumn{3}{|l|}{ Height } & \multirow{4}{*}{$\begin{array}{l}\text { Head Circumfe } \\
\text { AFNC } \\
(n=731) \\
M(\min , \max )\end{array}$} \\
\hline & AFNC & AFDC & $\mathbf{Z}$ & AFNC & AFDC & $\mathbf{Z}$ & AFNC & AFDC & $\mathbf{Z}$ & \\
\hline & $(n=731)$ & $(n=61)$ & & $(n=731)$ & $(n=61)$ & & $(n=731)$ & $(n=61)$ & & \\
\hline & $M(\min , \max )$ & $M(\min , \max )$ & & $M(\min , \max )$ & $M(\min , \max )$ & & $M(\min , \max )$ & $M(\min , \max )$ & & \\
\hline 0 & & & & $\begin{array}{l}3.19 \\
(1.16,5.25)\end{array}$ & $\begin{array}{l}3.14 \\
(1.59,4.67)\end{array}$ & -0.617 & $\begin{array}{l}49.36 \\
(32.00 \\
55.00)\end{array}$ & $\begin{array}{l}48.53 \\
(36.00,54.00)\end{array}$ & $-2.149 *$ & \\
\hline 1 & $\begin{array}{l}1.45 \\
(0.50,3.50)\end{array}$ & $\begin{array}{l}1.73 \\
(1.00,3.50)\end{array}$ & $-5.711^{\star}$ & $\begin{array}{l}4.25 \\
(1.50,6.50)\end{array}$ & $\begin{array}{l}4.04 \\
(1.82,5.40)\end{array}$ & -1.385 & $\begin{array}{l}54.34 \\
(41.00 \\
61.00)\end{array}$ & $\begin{array}{l}53.37 \\
(45.00,58.50)\end{array}$ & -1.671 & $37.11(30.20,40$ \\
\hline 6 & $\begin{array}{l}1.42 \\
(0.00,3.50)\end{array}$ & $\begin{array}{l}1.58 \\
(0.20,3.50)\end{array}$ & $-3.988^{\star}$ & $\begin{array}{l}7.96 \\
(3.20 \\
11.30)\end{array}$ & $\begin{array}{l}7.69 \\
(6.30 \\
10.10)\end{array}$ & $-2.039 *$ & $\begin{array}{l}67.44 \\
(53.00 \\
74.50)\end{array}$ & $\begin{array}{l}66.20 \\
(61.50,73.00)\end{array}$ & $-2.896^{\star}$ & $\begin{array}{l}43.49 \\
(35.80,47.20)\end{array}$ \\
\hline 12 & $\begin{array}{l}0.53 \\
(0.00,3.00)\end{array}$ & $\begin{array}{l}1.10 \\
(0.20,3.00)\end{array}$ & $-6.945^{\star}$ & $\begin{array}{l}9.58 \\
(4.10 \\
13.43)\end{array}$ & $\begin{array}{l}9.33 \\
(7.20 \\
11.10)\end{array}$ & $-2.083^{\star}$ & $\begin{array}{l}75.59 \\
(60.00 \\
84.00)\end{array}$ & $\begin{array}{l}74.68 \\
(69.00,80.00)\end{array}$ & $-2.541^{\star}$ & $\begin{array}{l}46.31 \\
(38.00,52.70)\end{array}$ \\
\hline 18 & $\begin{array}{l}0.04 \\
(0.00,2.50)\end{array}$ & $\begin{array}{l}0.55 \\
(0.20,2.50)\end{array}$ & $-12.470 *$ & $\begin{array}{l}10.82 \\
(4.95, \\
15.20)\end{array}$ & $\begin{array}{l}10.20 \\
(8.40 \\
13.00)\end{array}$ & $-2.894^{\star}$ & $\begin{array}{l}82.38 \\
(65.00 \\
91.50)\end{array}$ & $\begin{array}{l}81.00 \\
(74.50,88.00)\end{array}$ & $-3.314^{\star}$ & $\begin{array}{l}47.67 \\
(39.30,53.30)\end{array}$ \\
\hline 24 & $\begin{array}{l}0.00 \\
(0.00,0.00)\end{array}$ & $\begin{array}{l}0.44 \\
(0.10,1.30)\end{array}$ & $-28.097^{\star}$ & $\begin{array}{l}12.01 \\
(5.70 \\
16.90)\end{array}$ & $\begin{array}{l}11.35 \\
(9.60 \\
13.65)\end{array}$ & $-3.145^{\star}$ & $\begin{array}{l}88.11 \\
(70.50 \\
97.50)\end{array}$ & $\begin{array}{l}86.75 \\
(79.80,93.00)\end{array}$ & $-3.473^{\star}$ & $\begin{array}{l}48.60 \\
(40.50,53.60)\end{array}$ \\
\hline 30 & $\begin{array}{l}0.00 \\
(0.00,0.00)\end{array}$ & $\begin{array}{l}0.01 \\
(0.00,1.00)\end{array}$ & $-7.760^{\star}$ & $\begin{array}{l}13.12 \\
(6.40 \\
18.50)\end{array}$ & $\begin{array}{l}12.50 \\
(10.40 \\
15.10)\end{array}$ & $-3.218^{\star}$ & $\begin{array}{l}93.00 \\
(73.00 \\
102.90)\end{array}$ & $\begin{array}{l}91.34 \\
(83.00,99.00)\end{array}$ & $-3.430 *$ & $\begin{array}{l}49.19 \\
(40.70,54.40)\end{array}$ \\
\hline 36 & $\begin{array}{l}0.00 \\
(0.00,0.00)\end{array}$ & $\begin{array}{l}0.01 \\
(0.00,0.80)\end{array}$ & $-3.462^{\star}$ & $\begin{array}{l}14.23 \\
(6.90 \\
21.10)\end{array}$ & $\begin{array}{l}13.60 \\
(11.10 \\
16.20)\end{array}$ & $-3.809^{\star}$ & $\begin{array}{l}96.20 \\
(78.00 \\
107.60)\end{array}$ & $\begin{array}{l}94.20 \\
(85.70,102.30)\end{array}$ & $-4.237 *$ & $\begin{array}{l}49.79 \\
(41.80,54.70)\end{array}$ \\
\hline
\end{tabular}

AFNC, anterior fontanelle normal closure /AFDC, anterior fontanelle delayed closure;Mann-Whitney U test; *,P<0.05 
Table 3

The univariate analysis of perinatal and nutritional information $(\mathrm{N}=792)$

\begin{tabular}{|c|c|c|c|c|}
\hline \multirow[t]{2}{*}{ item } & \multicolumn{2}{|l|}{ category } & \multirow[t]{2}{*}{$\chi^{2} / Z$} & \multirow[t]{2}{*}{$\mathbf{P}$} \\
\hline & $\begin{array}{l}\text { AFNC } \\
(n=731) \%\end{array}$ & $\begin{array}{l}\text { AFDC } \\
(n=61)\end{array}$ & & \\
\hline $\begin{array}{l}\text { birth weight (g) } \\
<2500(\%) \\
2500 \sim 4000(\%) \\
>4000(\%)\end{array}$ & $\begin{array}{l}95(13.0) \\
608(83.2) \\
28(3.8)\end{array}$ & $\begin{array}{l}16(26.2) \\
37(60.7) \\
8(13.1)\end{array}$ & $21.218^{a}$ & $<0.001^{*}$ \\
\hline $\begin{array}{l}\text { birth length }(\mathrm{cm}) \\
<48(\%) \\
48 \sim 52(\%) \\
>52(\%)\end{array}$ & $\begin{array}{l}158(21.6) \\
546(74.7) \\
27(3.7)\end{array}$ & $\begin{array}{l}21(34.3) \\
38(62.3) \\
2(3.3)\end{array}$ & $5.289^{a}$ & 0.071 \\
\hline $\begin{array}{l}\text { gender } \\
\text { Male (\%) } \\
\text { Female (\%) }\end{array}$ & $\begin{array}{l}422(57.7) \\
309(42.3)\end{array}$ & $\begin{array}{l}28(45.9) \\
33(54.1)\end{array}$ & $3.210^{a}$ & 0.081 \\
\hline $\begin{array}{l}\text { delivery } \\
\text { vaginal delivery (\%) } \\
\text { cesarean delivery (\%) }\end{array}$ & $\begin{array}{l}154(21.1) \\
577(78.9)\end{array}$ & $\begin{array}{l}14(23.0) \\
47(77.0)\end{array}$ & $0.120^{a}$ & 0.745 \\
\hline $\begin{array}{l}\text { gestational age } \\
\text { premature (\%) } \\
\text { Mature (\%) }\end{array}$ & $\begin{array}{l}110(15.0) \\
621(85.0)\end{array}$ & $\begin{array}{l}16(26.2) \\
45(73.8)\end{array}$ & $5.262^{a}$ & $0.022^{\star}$ \\
\hline $\begin{array}{l}\text { fetus numbers } \\
1(\%) \\
\geq 1(\%)\end{array}$ & $\begin{array}{l}690(94.4) \\
41(5.6)\end{array}$ & $\begin{array}{l}56(91.8) \\
5(8.2)\end{array}$ & $0.689^{a}$ & 0.390 \\
\hline $\begin{array}{l}\text { gravidity } \\
\leq 3(\%) \\
>3(\%)\end{array}$ & $\begin{array}{l}700(95.8) \\
31(4.2)\end{array}$ & $\begin{array}{l}60(98.4) \\
1(1.6)\end{array}$ & $0.983^{a}$ & 0.504 \\
\hline $\begin{array}{l}\text { parity } \\
1(\%) \\
>1(\%)\end{array}$ & $\begin{array}{l}654(89.5) \\
77(10.5)\end{array}$ & $\begin{array}{l}54(88.5) \\
7(11.5)\end{array}$ & $0.053^{a}$ & 0.828 \\
\hline VA average before $2 y(I U)$ & 1602.3 & 1501.7 & $-1.604^{b}$ & 0.109 \\
\hline VD average before $2 y(I U)$ & 545.3 & 538.1 & $-1.177^{b}$ & 0.239 \\
\hline $\begin{array}{l}\text { The time of introducing } \\
\text { complementary food (months) }\end{array}$ & 8.02 & 6.40 & $-0.384^{b}$ & 0.701 \\
\hline \multicolumn{5}{|c|}{ AFNC, anterior fontanelle normal closure /AFDC, anterior fontanelle delayed closure } \\
\hline \multicolumn{5}{|l|}{ VA-Vitamin A, VD-Vitamin } \\
\hline b, Mann-Whitney U te & $P<0.05$ & & & \\
\hline
\end{tabular}


Table 4

The logistic regression of associated factors of $\operatorname{AFDC}(\mathrm{N}=792)$

\begin{tabular}{|c|c|c|c|c|c|}
\hline variables & BETA & SE & Wald $\chi^{2}$ & $\mathbf{P}$ & $\mathrm{OR}(95 \% \mathrm{Cl})$ \\
\hline birth weight & 0.001 & 0.000 & 10.006 & $0.002^{*}$ & $1.001(1.001,1.002)$ \\
\hline birth length & -0.251 & 0.090 & 7.811 & $0.005^{\star}$ & $0.778(0.653,0.928)$ \\
\hline AF size in $1 \mathrm{~m}$ & 1.434 & 0.247 & 33.692 & $<0.001^{*}$ & $4.196(2.585,6.810)$ \\
\hline gender & 0.616 & 0.288 & 4.571 & $0.033^{*}$ & $1.851(1.053,3.255)$ \\
\hline delivery & -0.094 & 0.342 & 0.076 & 0.783 & $0.910(0.466,1.779)$ \\
\hline gestational age & -0.588 & 0.525 & 1.256 & 0.262 & $0.555(0.198,1.779)$ \\
\hline fetus numbers & 0.464 & 0.576 & 0.648 & 0.421 & $1.590(0.514,4.921)$ \\
\hline gravidity & -1.160 & 1.071 & 1.174 & 0.279 & $0.313(0.038,2.556)$ \\
\hline parity & 0.528 & 0.451 & 1.367 & 0.242 & $1.695(0.700,4.106)$ \\
\hline VA average before $2 y$ & -0.001 & 0.001 & 1.870 & 0.172 & $0.999(0.998,1.000)$ \\
\hline VD average before $2 y$ & -0.001 & 0.002 & 0.006 & 0.936 & $1.000(0.996,1.004)$ \\
\hline $\begin{array}{l}\text { the time of introducing } \\
\text { complementary food }\end{array}$ & -0.071 & 0.113 & 0.397 & 0.529 & $0.931(0.747,1.162)$ \\
\hline Regression Equation & \multicolumn{5}{|c|}{$\chi^{2}=7.884, d f=8, R^{2}=0.171$} \\
\hline
\end{tabular}

\section{Figures}




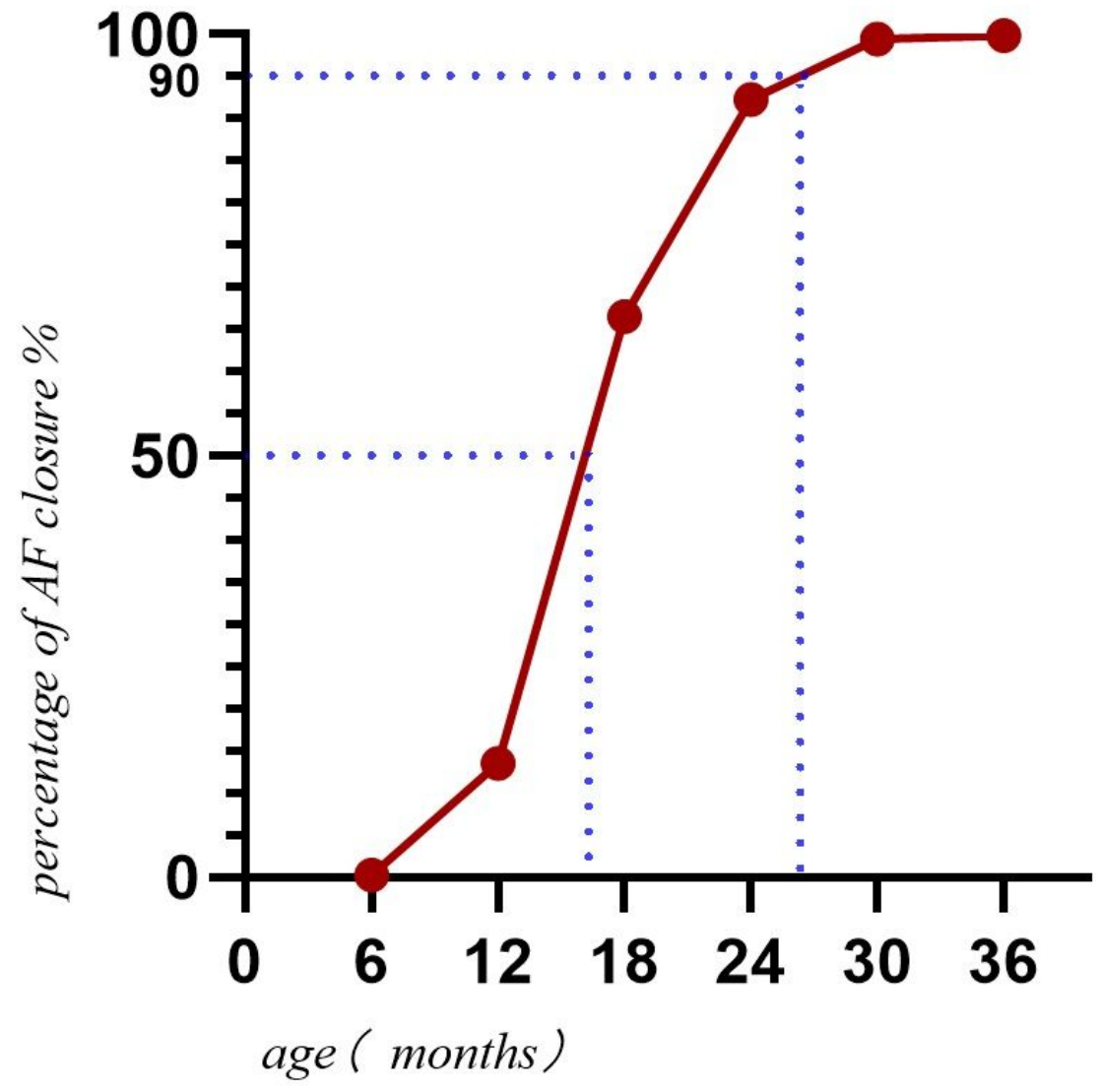

Fig. 1 the trend of AF clousure $(N=792)$

Figure 1

Figure 1 